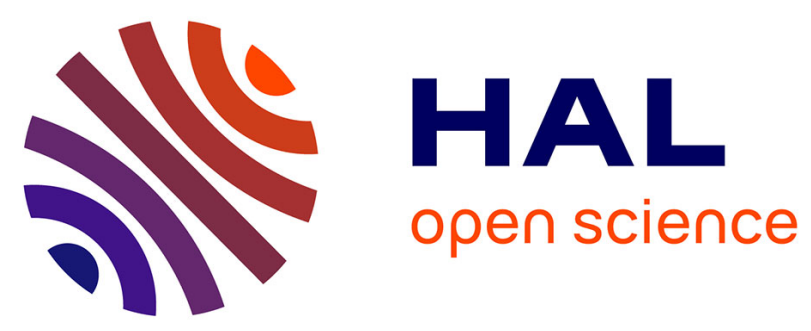

\title{
25 Gbps low-voltage hetero-structured silicon- germanium waveguide pin photodetectors for monolithic on-chip nanophotonic architectures
}

Daniel Benedikovic, Léopold Virot, Guy Aubin, Farah Amar, Bertrand Szelag, Bayram Karakus, Jean-Michel Hartmann, Carlos Alonso-Ramos, Xavier Le Roux, Paul Crozat, et al.

\section{To cite this version:}

Daniel Benedikovic, Léopold Virot, Guy Aubin, Farah Amar, Bertrand Szelag, et al.. 25 Gbps lowvoltage hetero-structured silicon- germanium waveguide pin photodetectors for monolithic on-chip nanophotonic architectures. Photonics research, 2019, 7 (47), pp.437-444. 10.1364/PRJ.7.000437 . hal-02543320

\author{
HAL Id: hal-02543320 \\ https://hal.science/hal-02543320
}

Submitted on 15 Apr 2020

HAL is a multi-disciplinary open access archive for the deposit and dissemination of scientific research documents, whether they are published or not. The documents may come from teaching and research institutions in France or abroad, or from public or private research centers.
L'archive ouverte pluridisciplinaire HAL, est destinée au dépôt et à la diffusion de documents scientifiques de niveau recherche, publiés ou non, émanant des établissements d'enseignement et de recherche français ou étrangers, des laboratoires publics ou privés. 


\title{
25 Gbps low-voltage hetero-structured silicon- germanium waveguide pin photodetectors for monolithic on-chip nanophotonic architectures
}

\author{
DANIEL BENEDIKOVIC, ${ }^{1, *}$ LÉOPOld VIROT, $^{2}$ GUY AUBIN $^{1}$, FARAH AMAR ${ }^{1}$, \\ BERTRAND SZELAG ${ }^{2}$, BAYRAM KARAKUS ${ }^{2}$, JEAN-MICHEL HARTMANN ${ }^{2}$, CARLOS

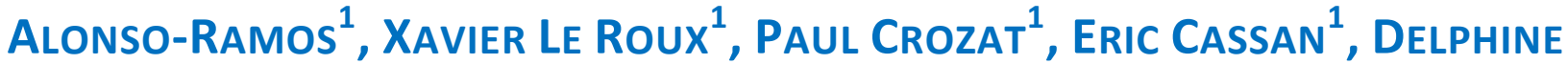 \\ Marris-Morini ${ }^{1}$, Charles Baudot ${ }^{3}$, Frédéric Boeuf $^{3}$, JeAn-MARC FÉdéli ${ }^{2}$, \\ CHRISTOPHE KOPP ${ }^{2}$ AND LAURENT VIVIEN ${ }^{1}$

\footnotetext{
${ }^{1}$ Centre de Nanosciences et de Nanotechnologies, CNRS, Univ. Paris-Sud, Université Paris-Saclay, C2N-Palaiseau, 91120 Palaiseau, France

${ }^{2}$ University Grenoble Alpes and CEA, LETI, Minatec Campus, F-38054 Grenoble, Grenoble Cedex, France

${ }^{3}$ Technology R\&D, STMicroelectronics SAS, 850 rue Jean Monnet -38920 Crolles, France

*Corresponding author: daniel.benedikovic@c2n.upsaclay.fr
}

Received XX Month XXXX; revised XX Month, XXXX; accepted XX Month XXXX; posted XX Month XXXX (Doc. ID XXXXX); published XX Month XXXX

\begin{abstract}
Near-infrared (near-IR) Germanium (Ge) photodetectors monolithically integrated on top of silicon-on-insulator (SOI) substrates are universally regarded as key enablers towards chip-scale nanophotonics, with applications ranging from sensing and health monitoring to object recognition and optical communications. In this work, we report on the high-data-rate performance pin waveguide photodetectors made of lateral hetero-structured SiliconGermanium-Silicon (Si-Ge-Si) junction operating under low reverse bias at $1.55 \mu \mathrm{m}$. The pin photodetector integration scheme considerably eases device manufacturing and is fully compatible with complementary metaloxide-semiconductor (CMOS) technology. In particular, the hetero-structured Si-Ge-Si photodetectors show efficiency-bandwidth products of $\sim 9 \mathrm{GHz}$ at $-1 \mathrm{~V}$ and $\sim 30 \mathrm{GHz}$ at $-3 \mathrm{~V}$, with a leakage dark-current as low as $\sim 150 \mathrm{nA}$, allowing a superior signal detection of high-speed data traffics. A bit-error-rate of $10^{-9}$ is achieved for conventional $10 \mathrm{Gbps}, 20 \mathrm{Gbps}$ and $25 \mathrm{Gbps}$ data rates, yielding optical power sensitivities of $-13.85 \mathrm{dBm},-12.70 \mathrm{dBm}$, and $11.25 \mathrm{dBm}$, respectively. This demonstration opens up new horizons towards cost-effective Ge pin waveguide photodetectors that combine fast device operation at low voltages with standard semiconductor fabrication processes, as desired for reliable on-chip architectures in next generation nanophotonics integrated circuits.
\end{abstract}

(C)

2018

Optical

Society

of

America

http://dx.doi.org/10.1364/AO.99.099999

\section{INTRODUCTION}

In order to meet the increasing demands of the information-driven society, various levels of communication systems call upon components able of handling dense data streams. Indeed, recently adopted copper-based interconnects, with their inferior electronic and thermal properties, cannot fully satisfy future data traffic requirements of cloud and data center industries in terms of bandwidth, speed, energy consumption, and cost [1-5].

Silicon nanophotonics, notably on silicon-on-insulator (SOI) substrates [5-8], has emerged as a promising platform to overcome deficient data traffic flows in on-chip interconnects [9-11]. In this field, optical photodetectors integrated on an accessible SOI technology are inevitable for myriad of applications ranging from optical communications, sensing or health monitoring to object recognition. However, silicon (Si), an indirect band-gap semiconductor with a cutoff wavelength of $\sim 1.1 \mu \mathrm{m}$, is not a reliable material for photodetection at near-infrared (near-IR) wavelengths, i.e. the $1.3-1.55 \mu \mathrm{m}$ spectral range historically harnessed by optical communication windows of low fiber attenuation and dispersion. To address this deficiency, rather expensive III-V compound semiconductors integrated on SOI wafers via flip-chip bonding or direct heteroexpitaxy can be used [11-13]. 
However, such an integration typically comes with added fabrication complexity and possibly some contamination of the Si complementary metal-oxide-semiconductor (CMOS) pilot lines.

As an alternative, germanium (Ge) has appeared as a prime choice for near-IR light detection [14-16, 29-46]. Ge's appeal comes from high optical absorption, good crystalline quality, and most importantly, a low-cost integration scheme that leverages processes and tools of $\mathrm{Si}$ CMOS foundries. Good quality Ge-based material can be obtained via various growth processes [17-23]. The use of Ge-based alloys can be envisioned in near-IR photodetectors, lasers $[24,25]$ and modulators $[26,27]$. Such components should ease the monolithic integration of complex functionalities in all group-IV nanophotonic chips, with prospects for nanoelectronics [28], as well.

Various types of waveguide-integrated Ge pin photodetectors have been investigated [29-46], since the early 2000s. The homojunction integration scheme [29-41], where both doping and metal via-contacts are implemented directly on the Ge layer, suffers from a deleterious absorption losses, however. The device photo-responsivity, a core requisite for competitive photonic receivers, is then reduced. Additionally, specific Ge technological steps are mandatory to fabricate such structures. Conversely, integration strategies that avoid junction formation on heavily-doped Ge regions and the use of metal via-plugs directly on Ge have been proposed and demonstrated [42-46]. Experimental realizations of Si-contacted Ge pin photodetectors have shown convincing device performances, approaching the standards set by III-V epitaxial heterostructures.

The ideal pin waveguide photodetector should have a high responsivity (quantum efficiency), a fast response, and a reduced power consumption, preferably with an easy to implement process flow available in photonic foundries. Therefore, advanced pin photodetector architectures that are not curtailed by traditional tradeoffs are definitely needed.

In the spirit of our previous proof-of-concept demonstrations [46], we report here on high-data-rate operation of pin waveguide photodetectors with a lateral Silicon-Germanium-Silicon (Si-Ge-Si) heterojunction. The butt-waveguide-coupling integration facilitates the fabrication and yields improved device performances. In particular, we achieve a low-bias pin photodetector operation, with an efficiencybandwidth product of $\sim 9 \mathrm{GHz}$ at $-1 \mathrm{~V}$ bias, $\sim 30 \mathrm{GHz}$ at $-3 \mathrm{~V}$ and a darkcurrent leakage lower than $150 \mathrm{nA}$. In addition, the close-up eyediagram show the ability of $\mathrm{Si}-\mathrm{Ge}-\mathrm{Si}$ photodetectors of preserving highspeed signal transmissions up to $40 \mathrm{Gbps}$. Last, but not least, a biterror-free operation, herein reported for the first time, reaching a level of $10^{-9}$ is obtained for data rates of $10 \mathrm{Gbps}, 20 \mathrm{Gbps}$, and $25 \mathrm{Gbps}$, providing received power sensitivities of $-13.85 \mathrm{dBm},-12.70 \mathrm{dBm}$, and $-11.25 \mathrm{dBm}$, respectively.

\section{PIN PHOTO-DIODE DESIGN AND FABRICATION}

Figure 1(a) shows a cross-sectional view of the pin waveguide photodetector formed by a lateral (across the horizontal $x$-axis) SiliconGermanium-Silicon (Si-Ge-Si) heterojunction. The germanium (Ge) pin photodetectors are implemented here on a standard silicon-oninsulator (SOI) waveguide platform, with 220-nm-thick silicon (Si) waveguides and $2-\mu \mathrm{m}$-thick buried oxide (BOX) layers. The intrinsic Ge region ( $i-\mathrm{Ge})$, serving as an absorption medium, is inherently defined by the thickness and the width $\left(h_{\mathrm{Ge}} \times w_{\mathrm{Ge}}\right)$ of the Ge layer. As illustrated in Fig. 1(a), the intrinsic Ge region is situated in a cavity ( $\left.h_{\text {Seed }}\right)$, with a target thickness of about $60 \mathrm{~nm}$, and laterally sandwiched between two Si slabs, with $p$-type ( $p$-Si) and $n$-type ( $n$-Si) dopings, respectively. The whole is positioned at the end of the $\mathrm{Si}$ waveguide for buttcoupling injection of light inside the photo-detector.
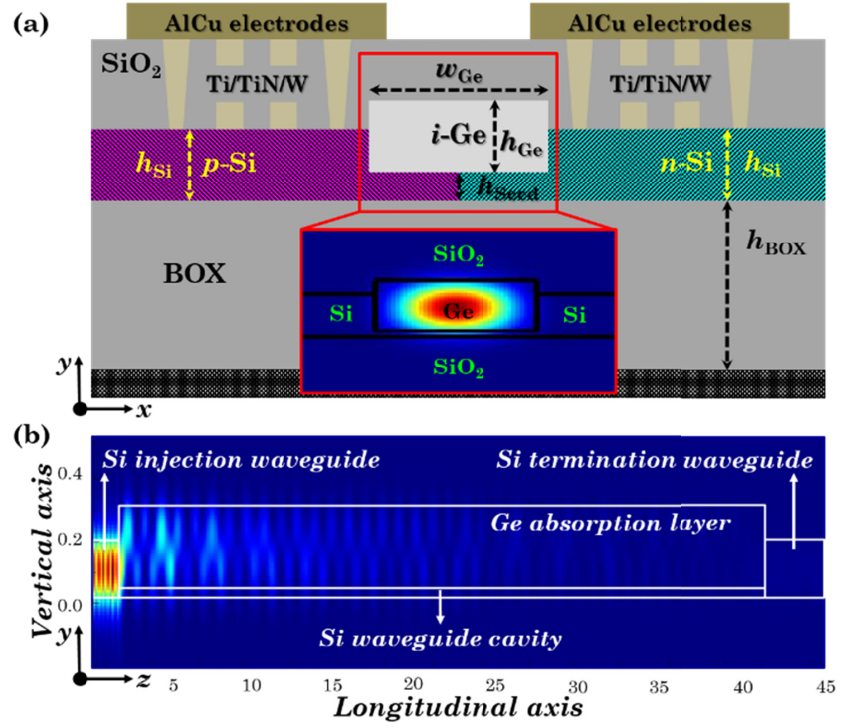

Fig. 1. (a) Transversal schematics ( $x-y$ plane) of the pin photodetector with a lateral Si-Ge-Si heterojunction architecture. Inset: Electric field profile of the fundamental TE-polarized optical mode in a $0.260-\mu \mathrm{m}$ thick and 1- $\mu \mathrm{m}$-wide heterostructured photodetector. (b) Longitudinal view ( $y$ - $z$ plane) of the optical intensity distribution in the $1-\mu \mathrm{m}$-wide and $40-\mu \mathrm{m}$-long butt-waveguide-coupled pin $\mathrm{Si}-\mathrm{Ge}-\mathrm{Si}$ photodetector, as obtained from 3-D FDTD simulations. The fundamental TE mode is injected from the Si waveguide on the left-hand-side.

The photodetector transversal dimensions have been optimized to yield the best device performances possible within a compact submicrometric area. The resulting device configuration was set to 0.260 $\mu \mathrm{m} \times 1 \mu \mathrm{m}\left(h_{\mathrm{Ge}} \times w_{\mathrm{Ge}}\right)$ in order to have an efficient propagation of transverse electrical (TE) modes at C-band (around $1.55 \mu \mathrm{m}$ ) wavelengths. As seen in the calculated electric field profile of the fundamental TE mode, shown in the inset of Fig. 1(a), the resulting optical power occupies almost completely the Ge area. More specifically, numerical calculations suggest that a 1- $\mu \mathrm{m}$-wide intrinsic region provides an excessively large power confinement of up to $87 \%$, while a comparatively low power of only $7 \%$ is present in the $p$-type and $n$-type doped $\mathrm{Si}$ regions. The improved field confinement is facilitated by the enhanced lateral index contrast, i.e. the index difference between the Ge core and the Si-doped regions, as compared to the conventional Ge pin homojunction configuration [29-41]. This optical design reduces the overlap between the evanescent field tails of the fundamental TE mode and lossy Si-doped slabs, substantially decreasing absorption losses from photo-generated carriers in the Sidoped regions. Furthermore, this also enables an efficient coupling of light from the injection $\mathrm{Si}$ waveguide into the fundamental TEpolarized mode in the device. The estimated coupling loss between the injection waveguide and the Ge photodetector is $-0.61 \mathrm{~dB}(\sim 87 \%$ of coupling efficiency). Figure 1(b) presents side schematics of the integrated butt-waveguide-coupled pin photodetector with optical intensity distribution, as modeled with a full-vectorial threedimensional (3-D) Finite-Difference Time Domain (FDTD) method [47], along the central plane of the structure. Since the Ge pin photodetector is an extension of the $\mathrm{Si}$ waveguide, the optical power is efficiently transferred from the injection waveguide into the intrinsic Ge zone.

The integration strategy, combining butt-waveguide-coupling and a lateral pin hetero-junction configurations, facilitates the fabrication of compact photodetectors with properly engineered waveguide. Such an approach substantially eases photodetector fabrication and yields 
improved device performances in terms of photo-responsivity and opto-electrical bandwidth $[43,44,46]$. In particular, such an approach enables to fabricate the metallic contacts directly on $n$-type and $p$-type doped $\mathrm{Si}$, which are robust steps in comparison to metallization on Ge. It should also be mentioned that the very same masking levels and mature manufacturing steps, such as ions implantation in $\mathrm{Si}$, are involved in the fabrication of optical modulators on Si platform [27], paving the way for monolithic integration of both passive and active photonic components with a significantly reduced number of process steps and thus cost.

The pin photodetectors with a lateral Si-Ge-Si heterojunction have been fabricated in CEA-LETI's cleanroom facilities on a fully integrated photonic platform with $200 \mathrm{~mm}$ SOI wafers and standard CMOS processes, as detailed in Ref. [46]. First, passive nanophotonic components, including interconnecting waveguides and fiber-to-chip surface grating couplers, have been fabricated via 193-nm deepultraviolet (deep-UV) photo-lithography and dry etching. Thermal oxidation has been performed to have a $\mathrm{SiO}_{2}$ cap layer prior to ion implantation. The $p$-type and $n$-type Si regions have been obtained by Boron and Phosphorous ion implantation. An oxide cladding has been deposited prior to the cavity patterning. Sub-sequently, the upper oxide has been etched down to the $\mathrm{Si}$ surface, followed by $\mathrm{Si}$ film patterning and deep-rib etching to form cavities with $\sim 60$-nm-thick $\mathrm{Si}$ floors above the BOX. A more than $1 \mu \mathrm{m}$ Ge layer was then selectively grown with $\mathrm{GeH}_{4}$ in those cavities via $450^{\circ} \mathrm{C} / 750^{\circ} \mathrm{C}$ Reduced Pressure - Chemical Vapor Deposition (RP-CVD) process, followed by a 1-hourlong annealing at $750^{\circ} \mathrm{C}$ and Chemical Mechanical Polishing (CMP) to reduce the Ge film thickness down to $\sim 260-\mathrm{nm}$ and recover a flat surface. Afterwards, a few- $\mu \mathrm{m}$-thick oxide cladding has been deposited for Ge passivation and insulation. 400-nm $\times 400-\mathrm{nm}$ vias have been patterned and etched down to Si doped regions. Ni-based silicidation was then conducted to improve contact resistance. At the end, Ti/TiN/W stack were used as metal plugs. Electrodes consisted in patterned AlCu layer.

\section{DEVICE EXPERIMENTS: RESULTS AND DISCUSSIONS}

\section{A. Static current-voltage measurements}

Conventional static current-voltage $(I-V)$ measurements, under darkand light-illuminated conditions, have been performed on the Si-Ge-Si pin photodetectors. More specifically, the light coming from a tunable laser has been coupled into the Si chip through a standard single-mode optical fiber (SMF-28). Optical interfacing has been realized thanks to surface grating couplers, optimized for a TE polarization and a central wavelength of $1.55 \mu \mathrm{m}$. The surface grating couplers were connected to short single-mode Si strip waveguides, with 220-nm-thick and 500nm-wide transversal geometry, delivering light into the Ge pin waveguide photodetector through butt-coupling scheme. The on-chip photodetectors were biased using an electrical probe.

$I-V$ characteristics of the leakage dark-current $\left(I_{\mathrm{d}}\right)$ and the generated photo-current $\left(I_{p}\right), \quad$ in 1 - $\mu \mathrm{m}$-wide by $40-\mu \mathrm{m}$-long $\mathrm{Si}-\mathrm{Ge}-\mathrm{Si}$ photodetectors, are shown in Fig. 2(a). Measured devices exhibit low dark-currents, $7 \mathrm{nA}$ under low-bias conditions (-1 V) for 5- $\mu \mathrm{m}$-long devices. The dark-current increases monotonously with the device length. The inset of Fig. 2(a) shows dark-current evolution as a function of the device junction area at $-1 \mathrm{~V}$ bias. The linear trend observed in this evolution suggests that the surface leakage is negligible compared to the bulk leakage. In addition, the dark-currents for $10 \mu \mathrm{m}, 20 \mu \mathrm{m}$ and $40 \mu \mathrm{m}$-long photodetectors are equal to $19 \mathrm{nA}, 43 \mathrm{nA}$, and $100 \mathrm{nA}$, respectively, (for a bias of $-1 \mathrm{~V}$ ). Further increases of reverse voltage yields moderate dark current increase, up to $150 \mathrm{nA}$ at $-4 \mathrm{~V}$ for the longest devices. The measured values compare favorably to previous reports on Si-contacted pin waveguide photodetectors [42-46] and are substantially lower than that of pure homo-junction devices with micro-metric cross-sectional areas [29-41]. Trap-assisted tunneling, dominating at low electric fields, and band-to-band tunneling, which governs carriers generation at moderate/high electric fields, are the main dark-current contributors. In agreement with expectations, hetero-structured $\mathrm{Si}-\mathrm{Ge}-\mathrm{Si}$ pin photodetectors provide leakage darkcurrents substantially lower than $1 \mu \mathrm{A}$ [16], making them suitable for high-speed and low-power consumption photonic receivers in established SOI nanophotonic platform.

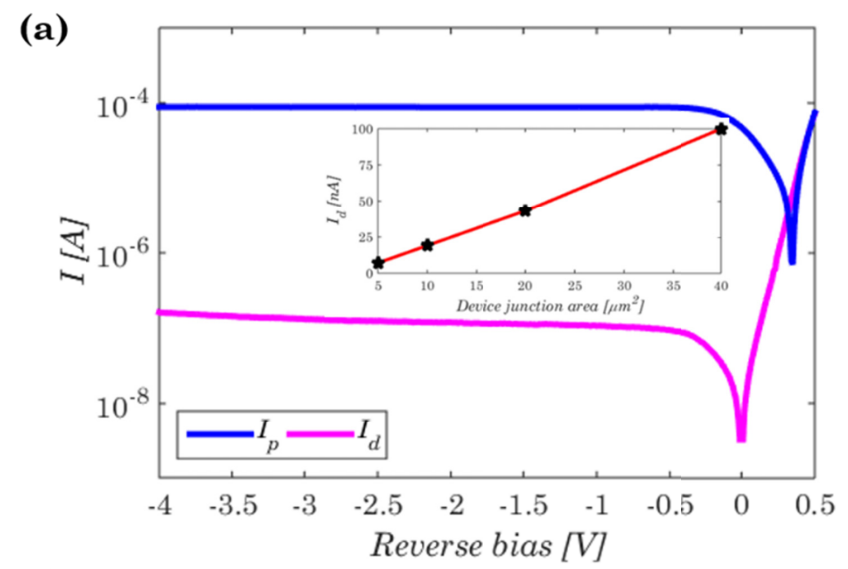

(b)
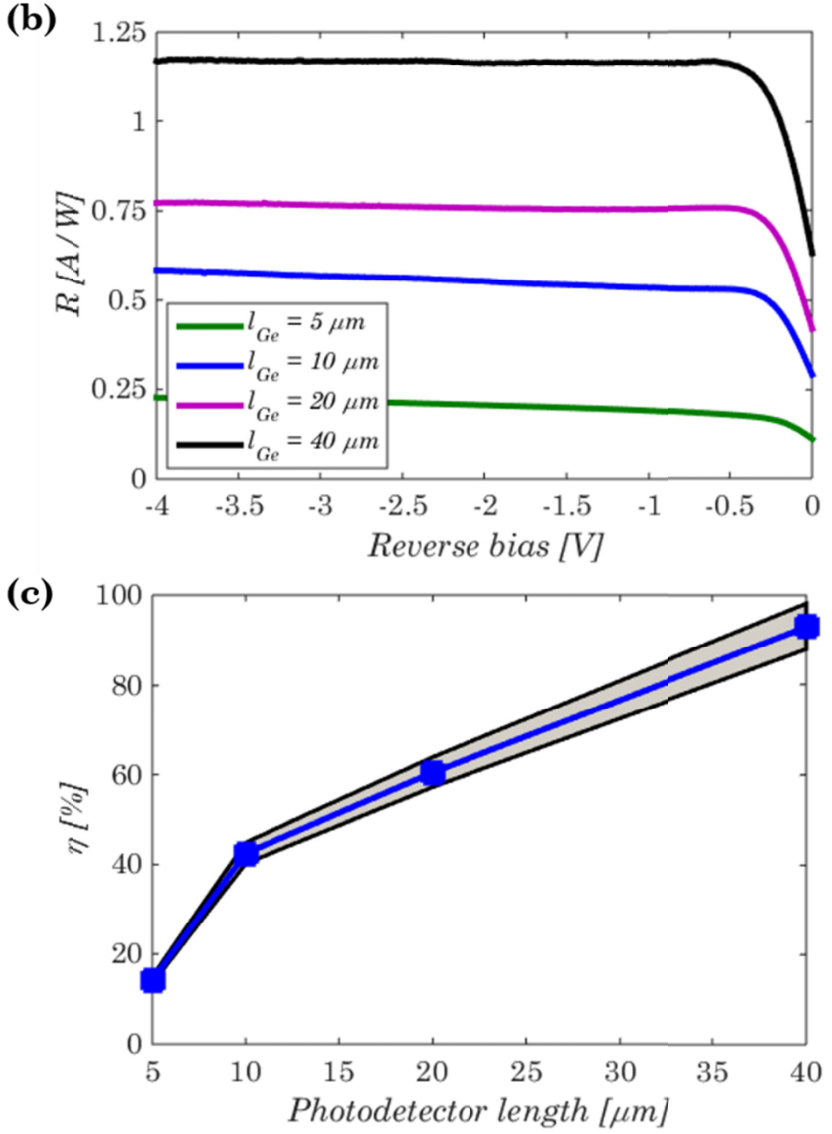

Fig. 2. (a) Static current-voltage (I-V) characteristics of $1-\mu \mathrm{m}$-wide by $40-\mu \mathrm{m}$-long hetero-structured pin photodetector, in dark- and lightilluminated states. Inset: Leakage dark-current evolution as a function of device junction area. Photodetectors were biased at -1 V. (b) Photoresponsivity as a function of the reverse voltage for different device lengths. (c) Quantum efficiency as a function of the device length under 
$-0.5 \mathrm{~V}$ reverse bias. The shadowed region denotes a range of quantum efficiencies for an estimated power uncertainty of $+/-0.24 \mathrm{~dB}$.

The responsivity of the photodetector $\left(R=I_{\mathrm{p}} / P_{\mathrm{i}}\right)$, has been calculated as the ratio between the generated photo-current (here, $I_{\mathrm{p}}$ stands for the net-light current, i.e. a photo-current without the contribution of the leakage dark-current) and the input optical power $\left(P_{\mathrm{i}}\right) . P_{\mathrm{i}}$ corresponds to the received power that reaches the photodiode, including the insertion loss of the fiber-chip surface grating coupler. The optical power coupled into the waveguide photodetector was estimated to be $-11.2 \mathrm{dBm}$ in these measurement conditions. The power uncertainty associated with this estimation is the in range of +/$0.24 \mathrm{~dB}$.

Figure 2(b) shows the photo-responsivity of a 1- $\mu$ m-wide detector as a function of the reverse voltage for different device lengths. The photodetector responsivity at $-1 \mathrm{~V}$ for the shortest (5- $\mu \mathrm{m}$-long) and the longest (40- $\mu \mathrm{m}$-long) devices are $0.19 \mathrm{~A} / \mathrm{W}$ and $1.19 \mathrm{~A} / \mathrm{W}$, respectively, among the highest values reported so far for Si-Ge-Si pin photodectors [42-46]. As shown in Fig. 2(b), the responsivities of Ge pin waveguide photodetectors reach their maxima at bias voltages as low as $-0.5 \mathrm{~V}$, one of the lowest reverse bias demonstrated so far. This behavior is consistently observed on all measured devices, independently on the device length. It is also worth highlighting that, beyond a $-0.5 \mathrm{~V}$ bias, the device responsivity reaches plateau and remains virtually flat, with a negligible voltage dependence. The presence of the strong built-in electrical field at low-bias states demonstrates the outstanding capability of hetero-structured pin photodetectors to sweep out the vast majority of the photo-generated carriers (electron-holes pairs) within their lifetime.

As a consequence, $\mathrm{Si}-\mathrm{Ge}-\mathrm{Si}$ hetero-structured photodetectors have an ultra-high quantum efficiency $(\eta)$, defined as follows: $\eta=(R \cdot 1.24) / \lambda$, where $\lambda$ is the operating wavelength of $1.55 \mu \mathrm{m}$. As shown in Fig. 2(c), the quantum efficiency increases from $\sim 14.2 \%$ for the shortest device (5- $\mu \mathrm{m}$-long) up to $\sim 95 \%$ for the longest device (40- $\mu \mathrm{m}$-long) at $-0.5 \mathrm{~V}$ reverse bias. In other words, this suggests that a $40-\mu \mathrm{m}$ photodetector is sufficiently long to absorb a $95 \%$ of the incoming light in the $\mathrm{Ge}$ waveguide. In addition, the estimated power uncertainty of $+/-0.24 \mathrm{~dB}$ results in changes in quantum efficiency, with a maximum range of $+/$ $4 \%$. This also confirms the superior collection efficiency of lateral pin $\mathrm{Si}-\mathrm{Ge}-\mathrm{Si}$ heterojunction photodetectors, i.e. the high conversion of incident photons into electrons contributing to the generated photocurrent.

\section{B. Small-signal radio-frequency measurements}

To assess the opto-electrical bandwidth properties of the heterostructured Si-Ge-Si photodetectors, we carried out small-signal radiofrequency (RF) measurements. Experiments were performed using a conventional RF-test set-up with a Lightwave Component Analyzer (LCA), with internally-built laser and modulator. Similarly to the static $I-V$ measurements, the optical interfacing that delivers the modulated light signal into the Si chip calls upon fiber-chip grating couplers. The pin waveguide photodetectors were reversely biased thanks to a biastee using a Keithley Source Measurement Unit. Prior to testing, the calibrations of the RF path was carried out to take into account the contributions from cables and probes. The small-signal RF experiments were performed by collecting the response of the $S_{21}$ transmission parameter in the LCA tool as a function of frequency.

Figure 3(a) shows a set of $S_{21}$ frequency responses, as retrieved from the small-signal RF measurements performed on Si-Ge-Si pin waveguide photodetector. The device was probed at various bias state in a range from $0 \mathrm{~V}$ to $-4 \mathrm{~V}$, using an average optical power coupled to the photodetector of $-11 \mathrm{dBm}$. The cut-off frequency of only $\sim 1.8 \mathrm{GHz}$ was measured at a bias of $0 \mathrm{~V}$. Indeed, the opto-electrical bandwidth is limited under the zero-bias state. This is due to the long transit time of carriers. In that case, photo-generated carriers can be efficiently collected only by the built-in electric field, which strength is, however, relatively weak under such biasing conditions [46].

(a)

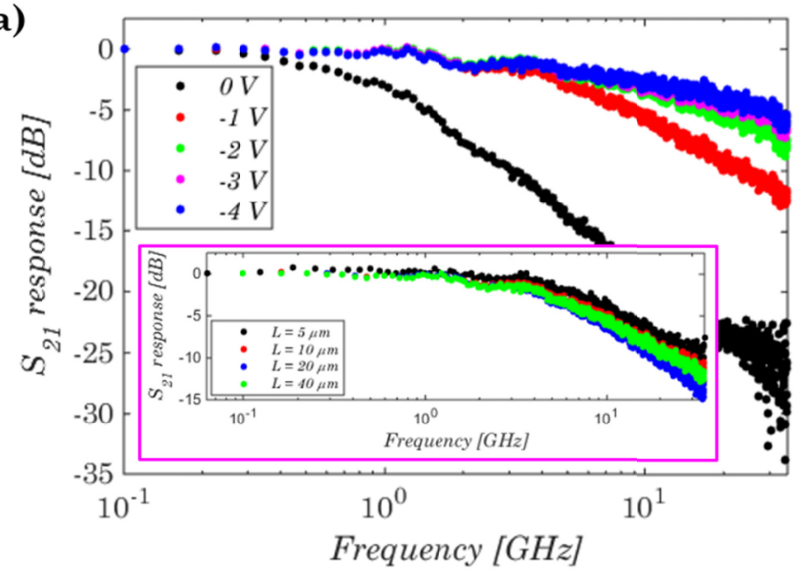

(b)

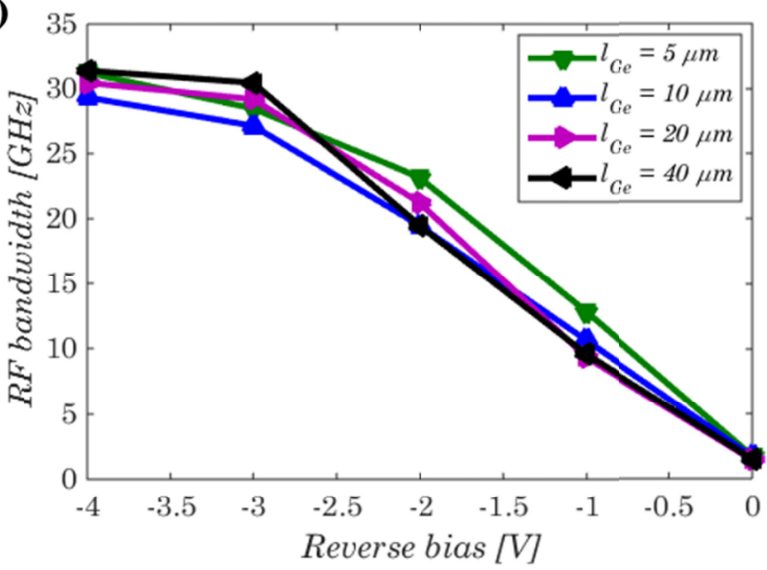

(c)

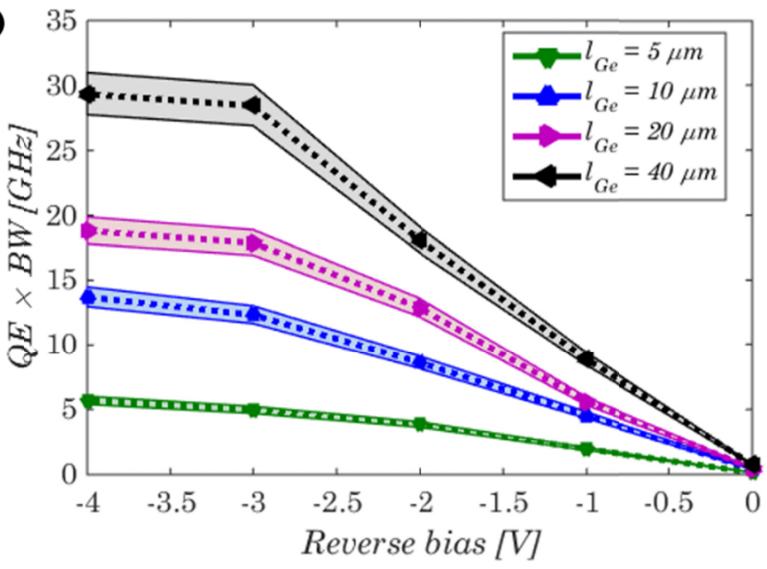

Fig. 3. (a) Small-signal RF measurements of the $S_{21}$ responses of the 1$\mu \mathrm{m}$-wide by $40-\mu \mathrm{m}$-long hetero-structured $\mathrm{Si}-\mathrm{Ge}-\mathrm{Si}$ photodetector, under different bias conditions in a range from $0 \mathrm{~V}$ to $-4 \mathrm{~V}$. Inset: $S_{21} \mathrm{RF}$ traces of different length $\mathrm{Si}-\mathrm{Ge}-\mathrm{Si}$ pin waveguide photodetectors biased at $-1 \mathrm{~V}$. (b) Opto-electrical bandwidths versus reverse bias for different device lengths. (c) Product of the quantum efficiency by the RF bandwidth versus reverse bias for $\mathrm{Si}-\mathrm{Ge}-\mathrm{Si}$ pin waveguide photodetectors with different lengths. The shadowed regions denote 
ranges of efficiency-bandwidth product for an estimated power uncertainty of $+/-0.24 \mathrm{~dB}$.

Those results are also consistent with the observed low responsivity at zero-bias. Such a behavior sets practical limits for a zero-bias operation of a hetero-structured Si-Ge-Si photodetector, as compared to pure Ge photodetectors [29-41]. Conversely, with increasing reverse bias, the enhanced electric field present inside the intrinsic Ge zone yields an increase of both the cut-off frequency and the responsivity. Specifically, as summed up in Fig. 3(b), the cut-off frequency becomes $\sim 13 \mathrm{GHz}$ at $-1 \mathrm{~V}$ reverse bias, while at $-2 \mathrm{~V}$, a $\sim 24 \mathrm{GHz}$ bandwidth is reached. For higher reverse biases of $-3 \mathrm{~V}$ and $-4 \mathrm{~V}$, the device optoelectrical bandwidth further increases up to $\sim 32 \mathrm{GHz}$. Comparable trends have been observed for all measured devices. The cut-off frequency of the hetero-structured $\mathrm{Si}-\mathrm{Ge}-\mathrm{Si}$ pin photodetectors becomes roughly independent on the device lengths, as shown in the inset of Fig. 3(a), with a $-1 \mathrm{~V}$ bias, i.e. the measured bandwidth is not limited by the RC delay.

Figure 3(c) shows the product of the quantum efficiency and the opto-electrical RF bandwidth, labeled as $Q E \times B W$, as a function of the reverse bias, for different Ge pin waveguide photodetector lengths. As expected, the highest efficiency-bandwidth product is achieved for the longest photodetector configuration, i.e. with a 40 - $\mu \mathrm{m}$-long intrinsic $\mathrm{Ge}$ zone. The efficiency-bandwidth product is around $9 \mathrm{GHz}$ at $-1 \mathrm{~V}$ and further raises to $30 \mathrm{GHz}$ for a $-3 \mathrm{~V}$ reverse voltage, with an estimated variation of $+/-2.3 \mathrm{GHz}$ for a previously introduced power uncertainty. These achievements show that Si-Ge-Si pin photodetectors are promising to simultaneously have high responsivity and high-speed operation.

\section{Large-signal data measurements: Eye-diagram acquisitions and bit-error-rate assessments}

The high-speed operation of hetero-structured Si-Ge-Si pin photodiodes was further investigated by performing data detection measurements. Experiments consisted in eye-diagram large-signal acquisitions and input power sensitivity assessments with bit-errorrate (BER) testing. Data were transmitted in non-return-to-zero (NRZ) optical modulation format. The pseudo-random-binary-sequence (PRBS) data pattern $2^{7}-1$ was considered for different rates of 10, 20, $25,28,32$, and $40 \mathrm{Gbps}$. The externally modulated laser wavelength was $1.55 \mu \mathrm{m}$. The transmitted signal was amplified with an Erbiumdoped fiber amplifier (EDFA), followed by an optical filter to reduce spontaneous emission noise. The average optical power was controlled thanks to a variable optical attenuator and an in-line powermeter. Optical TE polarization was adjusted with a polarization controller to optimize the intensity of the detected signal. The modulated signal was sent into the Si chip thanks to a surface grating coupler, followed by on-chip detection in the hetero-structured Si-Ge$\mathrm{Si}$ pin photodetector, without the use of integrated trans-impedance amplifier (TIA) or on-chip limiting amplifier (TA). Electrical data were retrieved through the $\mathrm{RF}$ set-up previously used for small-signal $\mathrm{RF}$ testing, by applying the reverse bias to the photodetector with the use of a RF probe connected to a bias-tee. Data were directly sent from the $\mathrm{RF}$ bias-tee output to a high-speed sampling oscilloscope, depicting eye diagrams. BER assessments were performed by inserting an external 38-GHz-broadband electrical amplifier between the RF bias-tee output and the BER detection module, whose minimum level requirement is $100 \mathrm{mV}$ peak-to-peak signal voltage. The measured eye diagrams and BER, for different transmission rates and various bias conditions, are shown in Fig. 4 and Fig. 5, respectively. Large-signal data testing was carried out in a $1-\mu \mathrm{m} \times 40-\mu \mathrm{m}$ (Ge width $\times$ Ge length) Si-Ge-Si photodetector.
In agreement with small-signal RF measurements, the eye diagram is closed at $0 \mathrm{~V}$ bias, as shown in Fig. 4 for a $10 \mathrm{Gbps}$ data rate. This behavior has also been observed for other transmission rates. A reverse bias increase ( $-0.5 \mathrm{~V}$ and $-1 \mathrm{~V}$ at $10 \mathrm{Gbps}$ line rate) results in a clear opening of the eye diagram, because of the generated electrical field within the intrinsic region, as explained previously. Clearly opened eye diagrams are obtained for conventional data rates of 10 Gbps, $20 \mathrm{Gbps}$, and $25 \mathrm{Gbps}$, with reverse voltages of $-1 \mathrm{~V},-2 \mathrm{~V}$, and -3 $\mathrm{V}$, enabling BER examination. Additionally, eye diagram apertures also suggest that high-speed signal detection is potentially achievable from $2 \mathrm{~V}$ biasing up to $40 \mathrm{Gbps}$ data speeds. The restricted photodetector bandwidth at $-1 \mathrm{~V}$ bias explains why eye diagrams are closing, as the data rate increases. Yet, the voltage adjustment possibility preserves high-bit-rate signals detection capability up to $40 \mathrm{Gbps}$.
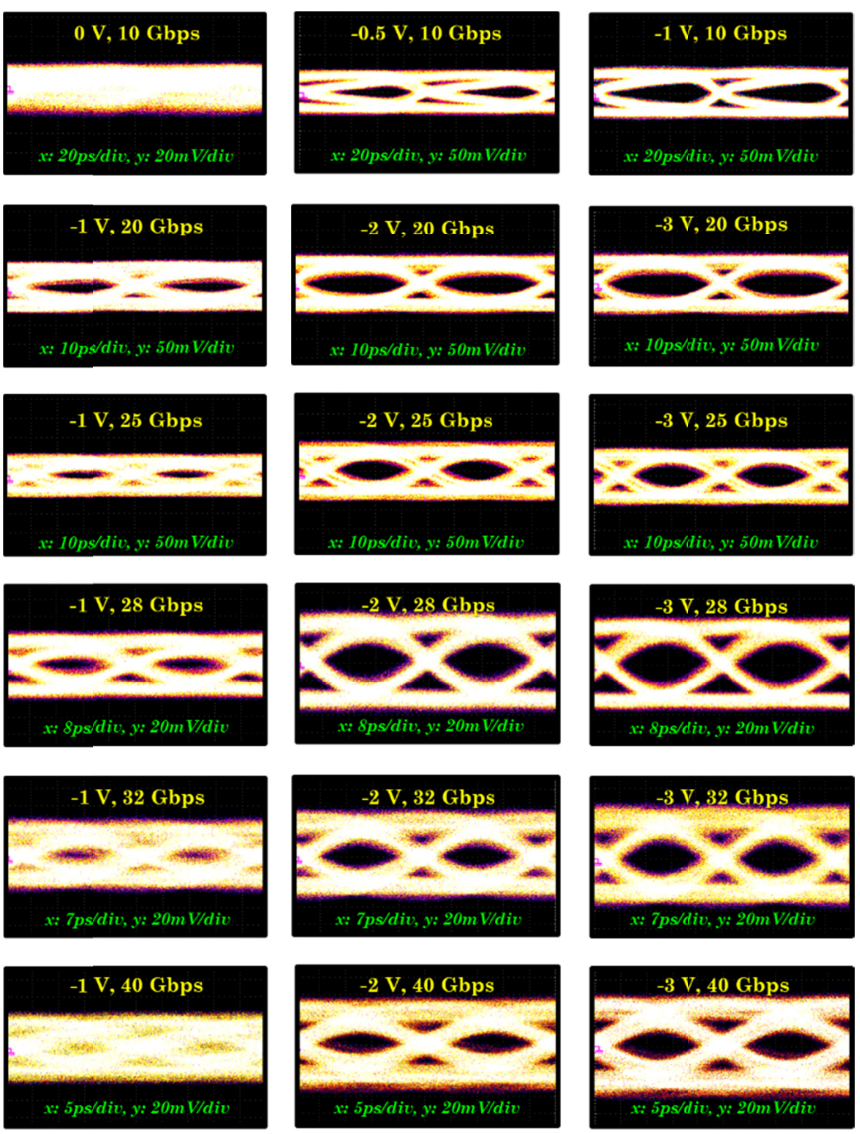

Fig. 4. Evolution of eye diagram apertures within a low-reverse-bias range at $10 \mathrm{Gbps}, 20 \mathrm{Gbps}, 25 \mathrm{Gbps}, 28 \mathrm{Gbps}, 32 \mathrm{Gbps}$, and $40 \mathrm{Gbps}$. Here, $x$ [ps/div] and $y[\mathrm{mV} / \mathrm{div}]$ correspond to the horizontal and vertical scope axis within the particular measurement setting. 1- $\mu \mathrm{m} \times$ 40- $\mu \mathrm{m}$ (Ge width $\times$ Ge length) Si-Ge-Si photodetector.

Fig. 5(a) shows BER measurements as a function of the received optical power for a $10 \mathrm{Gbps}$ data rate, under $-1 \mathrm{~V},-2 \mathrm{~V}$ and $-3 \mathrm{~V}$ bias conditions. Optical power sensitivities, defined as yielding a $10^{-9} \mathrm{BER}$, are equal to $-9.95 \mathrm{dBm},-12.75 \mathrm{dBm}$ and $-13.85 \mathrm{dBm}$ for those bias. Fig. 5(b) shows the measured BER for transmission data rates of 10 Gbps, $20 \mathrm{Gbps}$, and 25 Gbps under $-3 \mathrm{~V}$ bias. BER $10^{-9}$ optical power sensitivities of $-13.85 \mathrm{dBm},-12.70 \mathrm{dBm}$ and $-11.25 \mathrm{dBm}$ are associated to those data rates. It is worth noting that the low induced penalty measured when the bit rate increases from $10 \mathrm{Gbps}$ up to 20 Gbps is attributed to the fact that sensitivity at $10 \mathrm{Gbps}$ should be lower with a better suited electrical error detection chain with a much lower bandwidth. Lower peak-to-peak signal voltage requirement at the 
error detection module input should decrease sensitivity values as well.
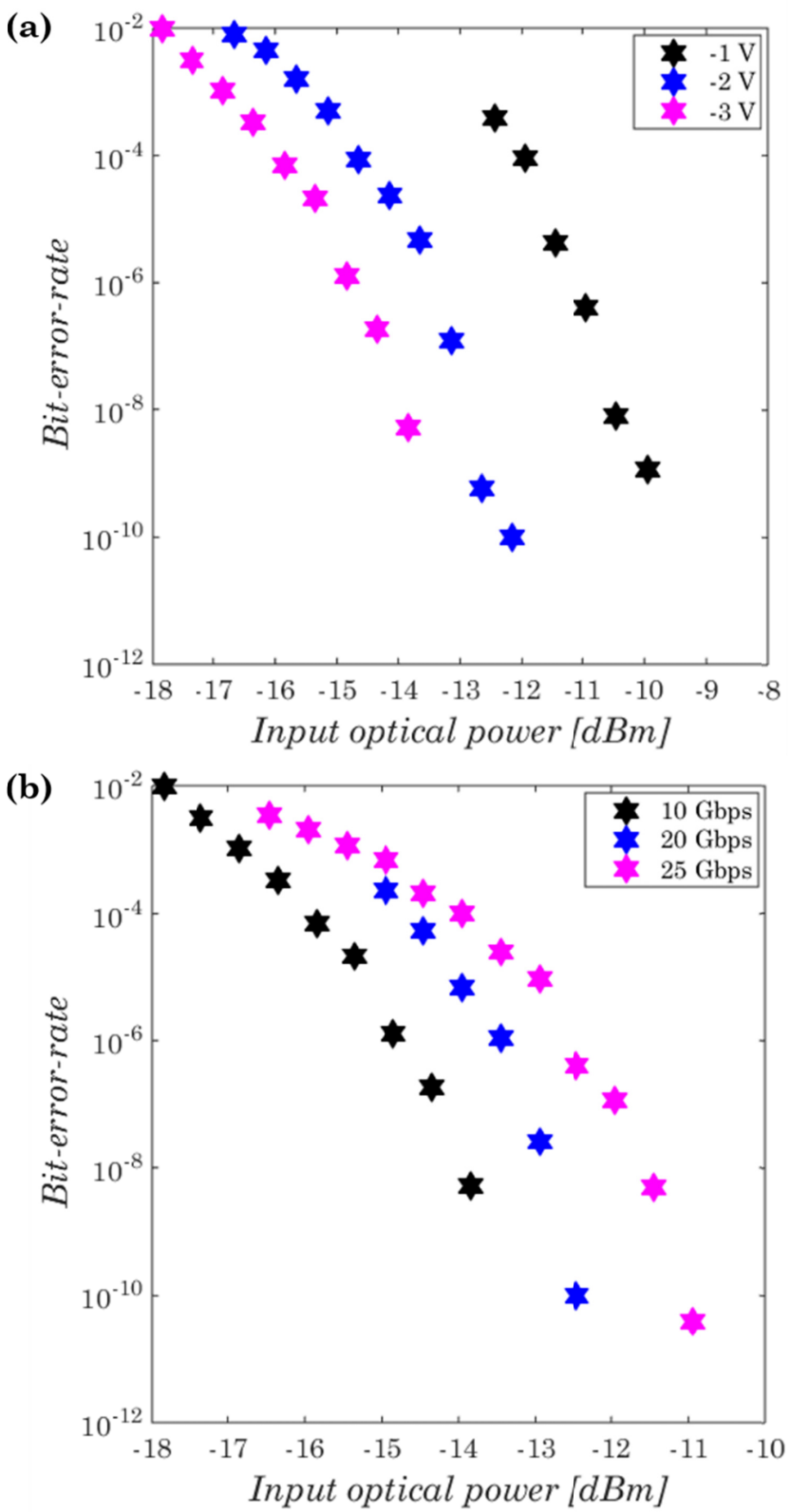

Fig. 5. Bit-error-rate measurements of the Si-Ge-Si pin waveguide photodetector as a function of the input optical power. BER assessments performed (a) at $10 \mathrm{Gbps}$ under low-reverse-bias states and (b) at $10 \mathrm{Gbps}, 20 \mathrm{Gbps}$, and $25 \mathrm{Gbps}$, all biased at $-3 \mathrm{~V} .1-\mu \mathrm{m} \times 40$ $\mu \mathrm{m}$ (Ge width $\times$ Ge length) Si-Ge-Si photodetector.

\section{CONCLUSIONS}

In summary, we have experimentally shown that pin waveguide photodetectors with lateral $\mathrm{Si}-\mathrm{Ge}-\mathrm{Si}$ junctions have superior performances, when operating under low-reverse-bias at $1.55 \mu \mathrm{m}$. The devices strongly benefit from the combination of butt-waveguidecoupling with lateral $\mathrm{Si}-\mathrm{Ge}-\mathrm{Si}$ pin junctions, resulting in compact devices with a definitely reduced fabrication complexity and substantially improved performances. More specifically, heterostructured pin waveguide photodetectors yield efficiency-bandwidth products of $\sim 9 \mathrm{GHz}$ at $-1 \mathrm{~V}, \sim 30 \mathrm{GHz}$ at $-3 \mathrm{~V}$ and dark-currents lower than $150 \mathrm{nA}$. Eye diagram inspections confirm that Si-Ge-Si pin photodetectors enable a detection of high-speed signals up to $40 \mathrm{Gbps}$. A bit-error-free operation of $10^{-9}$ is achieved for data rates of $10 \mathrm{Gbps}$, $20 \mathrm{Gbps}$, and $25 \mathrm{Gbps}$, with optical power sensitivities of $-13.85 \mathrm{dBm}$, $12.70 \mathrm{dBm}$, and $-11.25 \mathrm{dBm}$, respectively. This demonstration holds promising prospects for the development of high-speed, energyefficient and low-cost photodetectors at the chip-scale, which ultimately could usher a future generation of silicon nanophotonic architectures in optical integrated circuits.

Funding Information. H2020 European Research Council (ERC) (ERC POPSTAR - grant agreement No 647342).

\section{References}

1. L. Vivien and L. Pavesi, Handbook of Silicon Photonics (CRC Press, 2013).

2. M. Asghari and A. V. Krishnamoorthy, "Energy-efficient communication," Nat. Photonics 5, 268-270 (2011).

3. D. Thomson, A. Zilkie, J. E. Bowers, T. Komljenovic, G. T. Reed, L. Vivien, D. Marris-Morini, E. Cassan, L. Virot, J.-M. Fédéli, J.-M. Hartmann, J. H. Schmid, D.-X. Xu, F. Boeuf, P. O'Brien, G. Z. Mashanovich, and M. Nedeljkovic, "Roadmap on silicon photonics," J. Opt. 18, 073003 (2016).

4. K. Yamada, T. Tsuchizawa, H Nishi, R. Kou, T. Hiraki, K. Takeda, H. Fukuda, Y. Ishikawa, K. Wada, and T. Yamamoto, "High-performance silicon photonics technology for telecommunications applications," Sci. Technol. Adv. Mater. 15, 024603 (2014).

5. X. Chen, M. M. Milosevic, S. Stankovic, S. Reynolds, T. Dominguez-Bucio, K. Li, D. J. Thomson, F. Gardes, and G. T. Reed, "The Emergence of Silicon Photonics as a Flexible Technology Platform," P IEEE 106, 2101-2116 (2018)

6. R. Halir, A. Ortega-Moñux, D. Benedikovic, G. Z. Mashanovich, J. G. Wangüemert-Pérez, J. H. Schmid, Í. Molina-Fernández, and P. Cheben, "Subwavelength-Grating Metamaterial Structures for Silicon Photonic Devices," P IEEE 106, 2144-2157 (2018).

7. J. Chilles and S. Fathpour, "Silicon photonics beyond silicon-on-insulator," J. Opt. 19, 053001 (2017).

8. D. Marris-Morini, V. Vakarin, J. M. Ramirez, Q. Liu, A. Ballabio, J. Frigerio, M. Montesinos, C. Alonso-Ramos, X. Le Roux, S. Serna, D. Benedikovic, D. Chrastina, L. Vivien, and G. Isella, "Germanium-based integrated photonics from near- to mid-infrared applications," Nanophotonics 7, 1781-1793 (2018).

9. Y. Li, Y. Zhang, L. Zhang, and A. W. Poon, "Silicon and optical receiver based on hybrid silicon photonic devices for intra-datacenter applications: state of the art and perspectives," Photon. Res. 3, B10-B27 (2015).

10. A. V. Krishnamoorthy and D. A. B. Miller, "Scaling optoelectronic-VLSI circuits into the 21st century: A technology roadmap," IEEE J. Sel. Top. Quantum Electron. 22, 55-76 (1996).

11. G. Roelkens, L. Liu, D. Liang, R. Jones, A. Fang, B. Koch, and J. Bowers, "IIIV/silicon photonics for on-chip and intra-chip optical interconnects," Laser Photon. Rev. 4, 751-779 (2010).

12. O. Marshall, M. Hsu, Z. Wang, B. Kunert, C. Koos, and D. Van Thourhout, “Heterogeneous Integration on Silicon Photonics," P IEEE 106, 2258-2269 (2018).

13. T. Komljenovic, D. Huang, P. Pintus, M. A. Tran, M. L. Davenport, and J. E. Bowers, "Photonic Integrated Circuits Using Heterogeneous Integration on Silicon," P IEEE 106, 2246-2257 (2018).

14. S. Fama, L. Colace, G. Masini, G. Assanto, and H.-C. Luan, "High performance germanium-on-silicon detectors for optical communications," Appl. Phys. Lett. 81, 586-588 (2002).

15. S. J. Koester, J. D. Schaub, G. Delinger, and J. O. Chu, "Germanium-on-SOI infrared detectors for integrated photonic applications," IEEE J. Sel. Top. Quantum Electron. 12, 1489-1502 (2006).

16. J. Michel, J. Liu, and L. C. Kimerling, "High-performance Ge-on-Si photodetectors," Nat. Photonics 4, 527-534 (2010). 
17. T. A. Langdo, C. W. Leitz, M. T. Currie, E. A. Fitzgerald, A. Lochtefeld, and D. A. Antoniadis, "High quality Ge on Si by epitaxial necking," Appl. Phys. Lett. 76, 3700-3702 (2000).

18. J. M. Baribeau, T. E. Jackman, D. C. Houghton, P. Maigné, and M. W. Denhoff, "Growth and characterization of Si1-xGex and Ge epilayers on (100) Si," J. Appl. Phys. 63, 5738-5746 (1988).

19. H.-C. Luan, D. R. Lim, K. K. Lee, K. M. Chen, J. G. Sandland, K. Wada, and L. C. Kimerling, "High-quality Ge epilayers on Si with low threadingdislocation densities," Appl. Phys. Lett. 75, 2909-2911 (1999).

20. C. G. Littlejohns, M. Nedeljkovic, C. F. Mallinson, J. F. Watts, G. Z. Mashanovich, G. T. Reed, and F. Y. Gardes, "Next generation device grade silicon-germanium on insulator," Sci. Rep. 5, 8288 (2015).

21. C. G. Littlejohns, T. Dominguez Bucio, M. Nedeljkovic, H. Wang, G. Z. Mashanovich, G. T. Reed, and F. Y. Gardes, "Towards a fully functional integrated photonic-electronic platform via a single SiGe growth step," Sci. Rep. 6, 19425 (2016).

22. J.-M. Hartmann, J.-F. Damlencourt, Y. Bogumilowicz, P. Holliger, G. Roland, and T. Billon, "Reduced pressure-chemical vapor deposition of intrinsic and doped Ge layers on $\mathrm{Si}(001)$ for microelectronics and optoelectronics purposes," J. Crys. Growth 274, 90-99 (2005).

23. Y. H. Tan and C. S. Tan, "Growth and characterization of germanium epitaxial film on silicon (001) using reduced pressure chemical vapor deposition," Thin Solid Films 520, 2711-2716 (2012).

24. J. Liu, X. Sun, R. Camacho-Aguilera, L. C. Kimerling, and J. Michel, "Ge-onSi laser operating at room temperature," Opt. Lett. 35, 679-681 (2010).

25. R. E. Camacho-Aguillera, Y. Cai, N. Patel, J. T. Bessette, M. Romagnoli, L. C. Kimerling, and J. Michel, "An electrically pumped germanium laser," Opt. Express 20, 11316-11320 (2012).

26. G. T. Reed, G. Mashanovich, F. Y. Gardes, and D. J. Thomson, "Silicon optical modulators," Nat. Photonics 4, 518-526 (2010).

27. D. Marris-Morini, L. Virot, C. Baudot, J.-M. Fédéli, G. Rasigade, D. PérezGalacho, J.-M. Hartmann, S. Oliver, P. Brindel, P. Crozat, F. Boeuf, and L. Vivien, "A 40 Gbit/s optical link on a 300-mm silicon platform," Opt. Express 22, 6674-6679 (2014).

28. A. H. Atabaki, S. Moazeni, F. Pavanello, H. Gevorgyan, J. Notaros, L. Alloatti, M. T. Wade, C. Sun, S. A. Kruger, H. Meng, K. Al Qubaisi, I. Wang, B. Zhang, A. Khilo, C. V. Baiocco, M. A. Popović, V. M. Stojanović, and R. J. Ram, "Integrating photonics with silicon nanoelectronics for the next generation of systems on a chip," Nature 556, 349-354 (2018).

29. L. Colace and G. Assanto, "Germanium on silicon for near-infrared light sensing," IEEE Photonics J 1, 69-79 (2009).

30. T. Yin, R. Cohen, M. M. Morse, G. Sarid, Y. Chetrit, D. Rubin, and M. J. Paniccia, "31 GHz Ge n-i-p waveguide photodetectors on Silicon-onInsulator substrate," Opt. Express 15, 13965-13971 (2007).

31. L. Vivien, J. Osmond, J.-M. Fédéli, D. Marris-Morini, P. Crozat, J. F. Damlencourt, E. Cassan, Y. Lecunff, and S. Laval, " $42 \mathrm{GHz}$ p.i.n germanium photodetector integrated in a silicon-on-insulator waveguide," Opt. Express 17, 6252-6257 (2009).

32. D. Feng, S. Liao, P. Dong, N. Feng, N. Feng, H. Liang, D. Zheng, C. Kung, J. Fong, R. Shafilha, J. Cunningham, A. Krishnamoorthy, and M. Asghari, "High-speed Ge photodetector monolithically integrated with large crosssection silicon-on-insulator waveguide," Appl. Phys. Lett. 95, 261105 (2009).

33. J. Joo, S. Kim, I. G. Kim, K.-S. Jang, and G. Kim, "High-sensitivity 10 Gbps Ge-on-Si photoreceiver operating at $\lambda \sim 1.55 \mu \mathrm{m}$," Opt. Express 18, 1647416479 (2010).

34. S. Assefa, F. Xia, S. W. Bedell, Y. Zhang, T. Topuria, P. M. Rice, and Y. A. Vlasov, "CMOS-integrated high-speed MSM germanium waveguide photodetector," Opt. Express 18, 4986-4999 (2010).

35. S. Liao, N.-N. Feng, D. Feng, P. Dong, R. Shafilha, C.-C. Kung, H. Liang, W. Qian, Y. Liu, J. Fong, J. E. Cunningham, Y. Luo, and M. Asghari, “ $36 \mathrm{GHz}$ submicron silicon waveguide germanium photodetector," Opt. Express 19, 10967-10972 (2011).

36. C. T. DeRose, D. C. Trotter, W. A. Zortman, A. L. Starbuck, M. Fisher, M. R. Watts, and P. S. Davids, "Ultra compact $45 \mathrm{GHz}$ CMOS compatible
Germanium waveguide photodiode with low dark current," Opt. Express 19, 24897-24904 (2011).

37. L. Vivien, A. Polzer, D. Marris-Morini, J. Osmond, J. M. Hartman, P. Crozat, E. Cassan, C. Kopp, H. Zimmermann, and J.-M. Fédéli, "Zero-bias 40 Gbit/s germanium waveguide photodetector on silicon," Opt. Express 20, 10961101 (2012).

38. G. Li, Y. Luo, X. Zheng, G. Masini, A. Mekis, S. Sahni, H. Thacker, J. Yao, I. Shubin, K. Raj, J. E. Cunningham, and A. V. Krishnamoorthy, "Improving CMOS-compatible Germanium photodetectors," Opt. Express 20, 2634526350 (2012).

39. H. Pan, S. Assefa, W. M. J. Green, D. M. Kuchta, C. L. Schow, A. V. Rylyakov, B. G. Lee, C. W. Baks, S. M. Shank, and Y. A. Vlasov, "High-speed receiver based on waveguide germanium photodetector wire-bonded to 90nm SOI CMOS amplifier," Opt. Express 20, 18145-18155 (2012).

40. L. Virot, L. Vivien, J.-M. Fédéli, Y. Bogumilowitz, J.-M. Hartmann, F. Boeuf, P. Crozat, D. Marris-Morini, and E. Cassan, "High-performance waveguideintegrated germanium PIN photodiodes for optical communication applications," Photon. Res. 1, 140-147 (2013).

41. T.-Y. Liow, N. Duan, A. E.-J. Lim, X. Tu, M. Yu, and G.Q. Lo, "Waveguide $\mathrm{Ge} / \mathrm{Si}$ avalanche photodetector with a unique low-height-profile device structure," In Optical Fiber Communications Conference, OSA Technical Digest (online), (Optical Society of America, 2014), pp. M2G.6.

42. Y. Zhang, S. Yang, Y. Yang, M. Gould, N. Ophir, A. E.-J. Lim, G.-Q. Lo, Y P. Magill, K. Bergman, T. Baehr-Jones, Y and M. Hochberg, "A highresponsivity photodetector absent metal-germanium direct contact," Opt. Express 22, 11367-11375 (2014).

43. H. T. Chen, P. Verheyen, P. De Heyn, G. Lepage, J. De Coster, P. Absil, G. Roelkens, and J. Van Campenhout, "High-responsivity low-voltage 28$\mathrm{Gb} / \mathrm{s}$ Ge p-i-n photodetector with silicon contacts," IEEE/OSA J. Lightwave Technol. 33, 820-824 (2015).

44. H. Chen, P. Verheyen, P. De Heyn, G. Lepage, J. De Coster, S. Balakrishnan, P. Absil, W. Yao, L. Shen, G. Roelkens, and J. Van Campenhout, "-1 V 67 $\mathrm{GHz}$ bandwidth Si-contacted germanium waveguide $\mathrm{p}-\mathrm{i}$-n photodetector for optical links at 56 Gbps and beyond," Opt. Express 24, 4622-4631 (2016).

45. H. Chen, P. Verheyen, P. De Heyn, G. Lepage, J. De Coster, S. Balakrishnan, P. Absil, G. Roelkens, and J. Van Campenhout, "Dark current analysis in high-speed germanium p-i-n waveguide photodetectors," J. Appl. Phys. 19, 213105 (2016).

46. L. Virot, D. Benedikovic, B. Szelag, C. Alonso-Ramos, B. Karakus, J.-M. Hartmann, X. Le Roux, P. Crozat, E. Cassan, D. Marris-Morini, Ch. Baudot, F. Boeuf, J.-M. Fédéli, C. Kopp, and L. Vivien, "Integrated waveguide PIN photodiodes exploiting lateral Si/Ge/Si heterojunction," Opt. Express 16, 19487-19496 (2017).

47. Lumerical, Inc., Available: https://www.lumerical.com/. 


\section{Full reference list}

1. L. Vivien and L. Pavesi, Handbook of Silicon Photonics (CRC Press, 2013).

2. M. Asghari and A. V. Krishnamoorthy, "Energy-efficient communication," Nature Photonics 5, 268-270 (2011).

3. D. Thomson, A. Zilkie, J. E. Bowers, T. Komljenovic, G. T. Reed, L. Vivien, D. Marris-Morini, E. Cassan, L. Virot, J.-M. Fédéli, J.-M. Hartmann, J. H. Schmid, D.-X. Xu, F. Boeuf, P. O'Brien, G. Z. Mashanovich, and M. Nedeljkovic, "Roadmap on silicon photonics," Journal of Optics 18, 073003 (2016).

4. K. Yamada, T. Tsuchizawa, H Nishi, R. Kou, T. Hiraki, K. Takeda, H. Fukuda, Y. Ishikawa, K. Wada, and T. Yamamoto, "High-performance silicon photonics technology for telecommunications applications," Science and Technology of Advanced Materials 15, 024603 (2014).

5. X. Chen, M. M. Milosevic, S. Stankovic, S. Reynolds, T. Dominguez-Bucio, K. Li, D. J. Thomson, F. Gardes, and G. T. Reed, "The Emergence of Silicon Photonics as a Flexible Technology Platform," Proceedings of the IEEE 106, 2101-2116 (2018).

6. R. Halir, A. Ortega-Moñux, D. Benedikovic, G. Z. Mashanovich, J. G. Wangüemert-Pérez, J. H. Schmid, Í. Molina-Fernández, and P. Cheben, "Subwavelength-Grating Metamaterial Structures for Silicon Photonic Devices," Proceedings of the IEEE 106, 2144-2157 (2018).

7. J. Chilles and S. Fathpour, "Silicon photonics beyond silicon-on-insulator," Journal of Optics 19, 053001 (2017).

8. D. Marris-Morini, V. Vakarin, J. M. Ramirez, Q. Liu, A. Ballabio, J. Frigerio, M. Montesinos, C. Alonso-Ramos, X. Le Roux, S. Serna, D. Benedikovic, D. Chrastina, L. Vivien, and G. Isella, "Germanium-based integrated photonics from near- to mid-infrared applications," Nanophotonics 7, 1781-1793 (2018).

9. Y. Li, Y. Zhang, L. Zhang, and A. W. Poon, "Silicon and optical receiver based on hybrid silicon photonic devices for intra-datacenter applications: state of the art and perspectives," Photonics Research 3, B10-B27 (2015).

10. A. V. Krishnamoorthy and D. A. B. Miller, "Scaling optoelectronic-VLSI circuits into the 21st century: A technology roadmap," IEEE Journal of Selected Topics in Quantum Electronics 22, 55-76 (1996).

11. G. Roelkens, L. Liu, D. Liang, R. Jones, A. Fang, B. Koch, and J. Bowers, "IIIV/silicon photonics for on-chip and intra-chip optical interconnects," Laser \& Photonics Reviews 4, 751-779 (2010).

12. O. Marshall, M. Hsu, Z. Wang, B. Kunert, C. Koos, and D. Van Thourhout, "Heterogeneous Integration on Silicon Photonics," Proceedings of the IEEE 106, 2258-2269 (2018).

13. T. Komljenovic, D. Huang, P. Pintus, M. A. Tran, M. L. Davenport, and J. E. Bowers, "Photonic Integrated Circuits Using Heterogeneous Integration on Silicon," Proceedings of the IEEE 106, 2246-2257 (2018).

14. S. Fama, L. Colace, G. Masini, G. Assanto, and H.-C. Luan, “High performance germanium-on-silicon detectors for optical communications," Applied Physics Letters 81, 586-588 (2002).

15. S. J. Koester, J. D. Schaub, G. Delinger, and J. O. Chu, "Germanium-on-SOI infrared detectors for integrated photonic applications," IEEE Journal of Selected Topic in Quantum Electronics 12, 1489-1502 (2006).

16. J. Michel, J. Liu, and L. C. Kimerling, "High-performance Ge-on-Si photodetectors," Nature Photonics 4, 527-534 (2010).

17. T. A. Langdo, C. W. Leitz, M. T. Currie, E. A. Fitzgerald, A. Lochtefeld, and D. A. Antoniadis, "High quality Ge on Si by epitaxial necking," Applied Physics Letters 76, 3700-3702 (2000).

18. J. M. Baribeau, T. E. Jackman, D. C. Houghton, P. Maigné, and M. W. Denhoff, "Growth and characterization of Si1-xGex and Ge epilayers on (100) Si," Journal of Applied Physics 63, 5738-5746 (1988).

19. H.-C. Luan, D. R. Lim, K. K. Lee, K. M. Chen, J. G. Sandland, K. Wada, and L. C. Kimerling, "High-quality Ge epilayers on Si with low threadingdislocation densities," Applied Physics Letters 75, 2909-2911 (1999).

20. C. G. Littlejohns, M. Nedeljkovic, C. F. Mallinson, J. F. Watts, G. Z. Mashanovich, G. T. Reed, and F. Y. Gardes, "Next generation device grade silicon-germanium on insulator," Scientific Reports 5, 8288 (2015).
21. C. G. Littlejohns, T. Dominguez Bucio, M. Nedeljkovic, H. Wang, G. Z. Mashanovich, G. T. Reed, and F. Y. Gardes, "Towards a fully functional integrated photonic-electronic platform via a single SiGe growth step," Scientific Reports 6, 19425 (2016).

22. J.-M. Hartmann, J.-F. Damlencourt, Y. Bogumilowicz, P. Holliger, G. Roland, and T. Billon, "Reduced pressure-chemical vapor deposition of intrinsic and doped Ge layers on Si(001) for microelectronics and optoelectronics purposes," Journal of Crystal Growth 274, 90-99 (2005).

23. Y. H. Tan and C. S. Tan, "Growth and characterization of germanium epitaxial film on silicon (001) using reduced pressure chemical vapor deposition," Thin Solid Films 520, 2711-2716 (2012).

24. J. Liu, X. Sun, R. Camacho-Aguilera, L. C. Kimerling, and J. Michel, “Ge-onSi laser operating at room temperature," Optics Letters 35, 679-681 (2010).

25. R. E. Camacho-Aguillera, Y. Cai, N. Patel, J. T. Bessette, M. Romagnoli, L. C. Kimerling, and J. Michel, "An electrically pumped germanium laser," Optics Express 20, 11316-11320 (2012).

26. G. T. Reed, G. Mashanovich, F. Y. Gardes, and D. J. Thomson, "Silicon optical modulators," Nature Photonics 4, 518-526 (2010).

27. D. Marris-Morini, L. Virot, C. Baudot, J.-M. Fédéli, G. Rasigade, D. PérezGalacho, J.-M. Hartmann, S. Oliver, P. Brindel, P. Crozat, F. Boeuf, and L. Vivien, "A 40 Gbit/s optical link on a 300-mm silicon platform," Optics Express 22, 6674-6679 (2014).

28. A. H. Atabaki, S. Moazeni, F. Pavanello, H. Gevorgyan, J. Notaros, L. Alloatti, M. T. Wade, C. Sun, S. A. Kruger, H. Meng, K. Al Qubaisi, I. Wang, B. Zhang, A. Khilo, C. V. Baiocco, M. A. Popović, V. M. Stojanović, and R. J. Ram, "Integrating photonics with silicon nanoelectronics for the next generation of systems on a chip," Nature 556, 349-354 (2018).

29. L. Colace and G. Assanto, "Germanium on silicon for near-infrared light sensing," IEEE Photonics Journal 1, 69-79 (2009).

30. T. Yin, R. Cohen, M. M. Morse, G. Sarid, Y. Chetrit, D. Rubin, and M. J. Paniccia, " $31 \mathrm{GHz}$ Ge n-i-p waveguide photodetectors on Silicon-onInsulator substrate," Optics Express 15, 13965-13971 (2007).

31. L. Vivien, J. Osmond, J.-M. Fédéli, D. Marris-Morini, P. Crozat, J. F. Damlencourt, E. Cassan, Y. Lecunff, and S. Laval, “ $42 \mathrm{GHz}$ p.i.n germanium photodetector integrated in a silicon-on-insulator waveguide," Optics Express 17, 6252-6257 (2009).

32. D. Feng, S. Liao, P. Dong, N. Feng, N. Feng, H. Liang, D. Zheng, C. Kung, J. Fong, R. Shafilha, J. Cunningham, A. Krishnamoorthy, and M. Asghari, "High-speed Ge photodetector monolithically integrated with large crosssection silicon-on-insulator waveguide," Applied Physics Letters 95, 261105 (2009).

33. J. Joo, S. Kim, I. G. Kim, K.-S. Jang, and G. Kim, "High-sensitivity 10 Gbps Ge-on-Si photoreceiver operating at $\lambda \sim 1.55 \mu \mathrm{m}$," Optics Express 18, 16474-16479 (2010).

34. S. Assefa, F. Xia, S. W. Bedell, Y. Zhang, T. Topuria, P. M. Rice, and Y. A. Vlasov, "CMOS-integrated high-speed MSM germanium waveguide photodetector," Optics Express 18, 4986-4999 (2010).

35. S. Liao, N.-N. Feng, D. Feng, P. Dong, R. Shafilha, C.-C. Kung, H. Liang, W. Qian, Y. Liu, J. Fong, J. E. Cunningham, Y. Luo, and M. Asghari, " $36 \mathrm{GHz}$ submicron silicon waveguide germanium photodetector," Optics Express 19, 10967-10972 (2011).

36. C. T. DeRose, D. C. Trotter, W. A. Zortman, A. L. Starbuck, M. Fisher, M. R. Watts, and P. S. Davids, "Ultra compact $45 \mathrm{GHz}$ CMOS compatible Germanium waveguide photodiode with low dark current," Optics Express 19, 24897-24904 (2011).

37. L. Vivien, A. Polzer, D. Marris-Morini, J. Osmond, J. M. Hartman, P. Crozat, E. Cassan, C. Kopp, H. Zimmermann, and J.-M. Fédéli, "Zero-bias 40 Gbit/s germanium waveguide photodetector on silicon," Optics Express 20, 1096-1101 (2012).

38. G. Li, Y. Luo, X. Zheng, G. Masini, A. Mekis, S. Sahni, H. Thacker, J. Yao, I. Shubin, K. Raj, J. E. Cunningham, and A. V. Krishnamoorthy, "Improving CMOS-compatible Germanium photodetectors," Optics Express 20, 26345-26350 (2012). 
39. H. Pan, S. Assefa, W. M. J. Green, D. M. Kuchta, C. L. Schow, A. V.

Rylyakov, B. G. Lee, C. W. Baks, S. M. Shank, and Y. A. Vlasov, “High-speed receiver based on waveguide germanium photodetector wire-bonded to 90nm SOI CMOS amplifier," Optics Express 20, 18145-18155 (2012).

40. L. Virot, L. Vivien, J.-M. Fédéli, Y. Bogumilowitz, J.-M. Hartmann, F. Boeuf, P. Crozat, D. Marris-Morini, and E. Cassan, "High-performance waveguideintegrated germanium PIN photodiodes for optical communication applications," Photonics Research 1, 140-147 (2013).

41. T.-Y. Liow, N. Duan, A. E.-J. Lim, X. Tu, M. Yu, and G.Q. Lo, “Waveguide $\mathrm{Ge} / \mathrm{Si}$ avalanche photodetector with a unique low-height-profile device structure," In Optical Fiber Communications Conference, OSA Technical Digest (online), (Optical Society of America, 2014), pp. M2G.6.

42. Y. Zhang, S. Yang, Y. Yang, M. Gould, N. Ophir, A. E.-J. Lim, G.-Q. Lo, Y P. Magill, K. Bergman, T. Baehr-Jones, $Y$ and M. Hochberg, "A highresponsivity photodetector absent metal-germanium direct contact," Optics Express 22, 11367-11375 (2014).

43. H. T. Chen, P. Verheyen, P. De Heyn, G. Lepage, J. De Coster, P. Absil, G. Roelkens, and J. Van Campenhout, "High-responsivity low-voltage 28$\mathrm{Gb} / \mathrm{s}$ Ge p-i-n photodetector with silicon contacts," IEEE Journal of Lightwave Technology 33, 820-824 (2015).

44. H. Chen, P. Verheyen, P. De Heyn, G. Lepage, J. De Coster, S. Balakrishnan, P. Absil, W. Yao, L. Shen, G. Roelkens, and J. Van Campenhout, "-1 V 67 $\mathrm{GHz}$ bandwidth Si-contacted germanium waveguide $\mathrm{p}$-i-n photodetector for optical links at $56 \mathrm{Gbps}$ and beyond," Optics Express 24, 4622-4631 (2016).

45. H. Chen, P. Verheyen, P. De Heyn, G. Lepage, J. De Coster, S. Balakrishnan, P. Absil, G. Roelkens, and J. Van Campenhout, "Dark current analysis in high-speed germanium p-i-n waveguide photodetectors," Journal of Applied Physics 19, 213105 (2016).

46. L. Virot, D. Benedikovic, B. Szelag, C. Alonso-Ramos, B. Karakus, J.-M. Hartmann, X. Le Roux, P. Crozat, E. Cassan, D. Marris-Morini, Ch. Baudot, F. Boeuf, J.-M. Fédéli, C. Kopp, and L. Vivien, "Integrated waveguide PIN photodiodes exploiting lateral Si/Ge/Si heterojunction," Optics Express 16, 19487-19496 (2017).

47. Lumerical, Inc., Available: https://www.lumerical.com/. 